\title{
Tutoring EFL Students in Portugal: Rethinking writing center methodology
}

\author{
Maria Inês Caldeira de Almeida ${ }^{1}$, Sydelle de Souza ${ }^{2,3}$ \\ ${ }^{1}$ CEAUL, Universidade de Lisboa, Portugal \\ ${ }^{2}$ Centro de Linguística, Universidade de Lisboa, Portugal \\ ${ }^{3}$ Faculdade de Letras, Universidade de Lisboa, Portugal \\ https://doi.org/10.36505/ExLing-2020/11/0019/000434
}

\begin{abstract}
The writing center at the University of Lisbon adopts a widely implemented tutoring model - a non-directive approach, focusing on content and organization (higher-order concerns), and grammar and vocabulary (lower-order concerns). This study aims to challenge this model from an English as a Foreign Language (EFL) perspective by reporting and analyzing the results of a qualitative survey of 6 tutors regarding their work at the center. Results show that although all tutors comply with the imported tutoring model, most report difficulties in implementing one or both of its central principles. Therefore, EFL writing centers should harbor a flexible methodology wherein addressed concerns are context-dependent and constantly renegotiated during writing sessions, which could have pedagogical implications in the EFL classroom.
\end{abstract}

Keywords: EFL, Academic Writing, Writing Center Methodology, Portugal

\section{Introduction}

As English has become an essential learning and publication tool in academia (Curry \& Lillis, 2004; Graddol, 2006), the popularity of writing centers has increased outside of the United States (Severino \& Cogie, 2004). The writing center at the University of Lisbon helps students improve their English academic writing skills, adopting a widely implemented tutoring philosophy based on non-directive methods and a hierarchized dichotomy between higherorder and lower-order concerns.

This study examines and challenges such a model from an English as a Foreign Language (EFL) perspective, considering the tutors and writers' specific linguistic background at a Portuguese university versus American writing centers.

\section{Theoretical background}

In the Unites States, writing centers have been shaped by the notions of collaborative learning and writing as both a process and a social activity (Cooper, 1986; Ede, 1989) making these centers places where students, rather than being regarded as passive subjects, can participate in the knowledge building process (Bruffee, 1995). Despite this rejection of "traditional

ExLing 2020: Proceedings of 11 th International Conference of Experimental Linguistics, 12-14 October 2020, Athens, Greece 
hierarchies" (Lunsford, 1991), the tutor and writer are not on equal terms, as the latter understands the assignment and its subject, whereas the former possesses knowledge concerning academic discourse and written English (Bruffee, 1995).

In his landmark article on tutoring methodology, Brooks (1991) argues for a "minimalist" approach to tutoring, making the writer "the only active agent in improving the paper." Tutors should help students without direct intervention, avoiding the work of the editor and accusations of plagiarism, while focusing on guiding students through the process of writing. They should not make direct changes to a text, but help students improve as writers, pushing them to find and correct any issues themselves. Thus, as stated by Gillespie and Lerner (2008), an ideal tutorial "would look like two peers having a conversation about writing," where the tutor, instead of directly commenting on a student's work, should prioritize a mostly Socratic questioning method, encouraging the writer to think about his text. Such an approach favored the development of a tutoring procedure that defines higher-order concerns as dealing with anything that is not related to "grammar or word choice" (Gillespie \& Lerner, 2008). Therefore, content and organization matters are prioritized in writing center sessions over grammar and correctness, which are considered lower-order concerns.

However, this approach does not take into account the needs of second language writers, who see the writing center "as a place to learn from their tutors both the rhetorical and the linguistic dimensions of writing" (Severino \& Cogie, 2004). Thus, following North's (1984) notion that a writing center should define its work "in terms of the writer it serves," it is paramount for each center to consider the linguistic background of both their tutors and tutees when defining its working methodology. An inability to do so has already caused tensions between the non-directive and directive tutoring approaches, as well as frustration among tutors who feel pressured to respect the established hierarchy between higher-order and lower-order concerns (Blau \& Hall, 2002; Nicklay, 2012; Severino \& Cogie, 2004). Yet, tutoring methodology for EFL writing centers, where both tutor and tutee are second language writers and the linguistic knowledge each brings to the session may be considerably different, remains largely unexplored. Therefore, the aim of the present study is to bring this discussion to the table as the first step towards accomplishing a long-term goal-to construct a methodology suitable for EFL writing centers that considers the linguistic background of writers and tutors alike.

\section{Methodology}

This study used Microsoft Forms to create and execute an anonymous online qualitative survey containing Likert-type, multiple choice, and long answer questions. The questionnaire was divided into three sections relating to: (i) the tutors' linguistic background and English proficiency, (ii) the writing center's 
tutoring philosophy, i.e., non-directive methods and the hierarchy established between concerns, and (iii) the tutors' overall assessment of their work and experience at the center.

Although the writing center has many tutors ${ }^{1}$, only those who volunteered for a minimum of two semesters were asked to take this survey. Thus, six tutors $(1 \mathrm{~F}, 5 \mathrm{M})$ with a mean age of 26 years $( \pm 2.79)$ participated in this qualitative survey. Five were native speakers of European Portuguese, and one was a native speaker of German. All self-reported a high proficiency in English (C1C2 CEFR) across all competencies and learned it pre-puberty $\left(\mathrm{M}_{\mathrm{Age}}=9.5\right.$ years), i.e., within the critical period of language acquisition.

\section{Results and discussion}

Results show that although all tutors comply with the imported tutoring model, most report difficulties in implementing one or both of its central principles. Regarding the hierarchy established between concerns, only one tutor affirms to have frequently addressed higher-order concerns, while half report that the students' level of proficiency in English required them to focus on lower-order ones. Thus, most tutors often felt the need to prioritize syntax-level issues, subverting the hierarchy usually established between concerns. The need for this change can be explained by taking into account the tutees' level of English proficiency, as a high frequency of lexico-grammatical issues in a text can lead to incomprehension, making lower-order concerns more relevant to address than organization or content.

With respect to the non-directive methodology, four tutors state that only a few students would not have benefitted from more direct guidance. Furthermore, although all tutors claimed to have prioritized organization and content issues, they were confronted with grammatical concerns more frequently than they were trained to address, reportedly dealing with lowerorder issues in a quarter of all writing conferences. Consequently, the nature of such concerns and the students' linguistic background made it necessary to put aside minimalist tutoring methodology and focus on issues directly. Although such an approach went against traditional writing center philosophy, the students' limited knowledge of the English language could not provide them with enough autonomy to allow for the correction of their own mistakes. As a result, tutors were unable to elicit answers from the writers, making it necessary to switch to a more direct methodology.

\section{Conclusion}

Implementing a mostly Socratic methodology, paired with hierarchized and rigid concepts of higher-order and lower-order concerns does not facilitate the tutors' task and could hinder the creation of learning opportunities. Thus, it is necessary to develop a writing center philosophy catering to the English academic writing needs of L1 Portuguese students. Moreover, in EFL writing 
centers, mostly non-directive tutoring should give way to a flexible methodology wherein addressed concerns are context-dependent and should be constantly renegotiated during writing conferences.

As this writing center is in its nascent stages, our sample size is limited. Therefore, future work should also consider the experience of EFL tutees while developing similar strategies in linguistically diverse academic contexts. This could also have pedagogical implications in the EFL classroom.

\section{Notes}

1. Both the authors of this paper are also tutors at the same writing center. They did not take the survey to avoid any conflict of interest.

\section{References}

Blau, S., Hall, J. 2002. Guilt-free Tutoring: Rethinking How We Tutor Non-NativeEnglish-Speaking students. The Writing Center Journal, 23(1), 23-44.

Brooks, J. 1991. Minimalist Tutoring: Making Students Do All the Work. The Writing Lab Newsletter, 15(6), 1-4. https://clas.sa.ucsb.edu/docs/defaultsource/resources-writing/minimalist-tutoring.pdf?sfvrsn=3e9d2bfb_0

Bruffee, K.A. 1995. Peer tutoring and the "Conversation of Mankind." Landmark Essays on Writing Centers, 87-98.

Cooper, M.M. 1986. The Ecology of Writing. College English, 48(4), 364. https://doi.org/10.2307/377264

Ede, L. 1989. Writing as a Social Process: A Theoretical Foundation. The Writing Center Journal, 9(2), 3-13. https://doi.org/10.1017/cbo9781139173674.015

Gillespie, P., Lerner, N. 2008. The Longman Guide to Peer Tutoring (2nd ed.). Pearson.

Lunsford, A. 1991. Collaboration, Control, and the Idea of a Writing Center. In "The Idea of a Writing Center": Building a Theoretical Foundation (pp. 92-99).

Nicklay, J. 2012. Got Guilt? Consultant Guilt in the Writing Center Community. The Writing Center Journal, 32(1), 14-27.

North, S. 1984. The Idea of A Writing Center. College English, 46(5), 433-446. https://doi.org/10.1017/CBO9781107415324.004

Severino, C., Cogie, J. 2004. Writing centers and second and foreign language writers. Journal of Second Language Writing, 13(3), 165-172. https://doi.org/10.1515/9781614511335-024 